\title{
Dietary considerations in the evaluation and management of
}

\section{nocturia [version 1; peer review: 2 approved]}

\author{
Upeksha S Alwis (D1), Thomas F Monaghan (iD)2, Rebecca Haddad3,4, \\ Jeffrey P Weiss², Saskia Roggeman (iD), Erik Van Laecke1, Johan Vande Walle (iD), \\ Alan J Wein' ${ }^{6}$ Karel Everaert(iD1
}

\footnotetext{
${ }^{1}$ Department of Human Structure and Repair, Ghent University Hospital, Ghent, Belgium

2Department of Urology, State University of New York Downstate Health Sciences University, Brooklyn, New York, USA

${ }^{3}$ Sorbonne Université, UPMC Univ Paris 06, AP-HP, GRC 01, Groupe de Recherche Clinique en Neuro-Urologie (GREEN), Service de Rééducation Neurologique, AP-HP, Paris, France

${ }^{4}$ Department of Urology, Ghent University Hospital, Ghent, Belgium

${ }^{5}$ Department of Pediatric Nephrology, Ghent University Hospital, Ghent, Belgium

${ }^{6}$ Department of Urology, Perelman School of Medicine at the University of Pennsylvania, Philadelphia, PA, USA
}

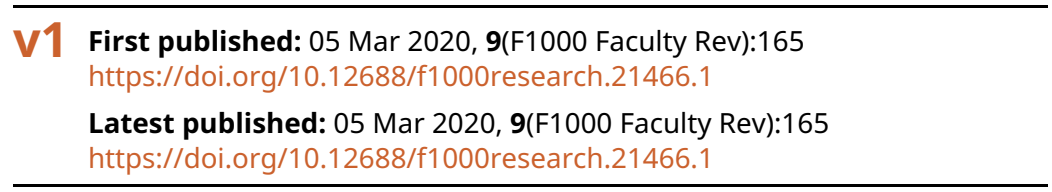

\section{Abstract}

Aim: This narrative review investigates the effect of dietary intake on nocturnal voiding severity. The primary aims of this review are to provide a framework for future research and ultimately contribute to more comprehensive, lifestyle-centered guidelines for the management of nocturia.

Methods: A literature search was conducted in Web of Science, PubMed, and Google Scholar databases using the keywords "nocturia", "diuresis", "natriuresis", "food", "diet", and "nutrients". Results: High fruit and vegetable consumption was negatively associated with nocturia. High intake of tea and dietary sodium showed a positive association with nocturia. Several foods have also been directly linked to changes in diuresis rate, glycemic control, and endogenous serum melatonin concentration, offering potential mechanisms for this observed effect. Overall quality of the evidence was low.

Conclusion: At present, there is limited evidence to suggest that certain foods, electrolytes, and specific compounds may contribute to the pathogenesis of nocturia. A greater understanding of the impact of food and nutrients on body fluid metabolism is needed to further refine the evaluation and treatment of nocturia.

\section{Keywords}

Nocturia, Food, Diet, Nutrients

\author{
Open Peer Review \\ Approval Status \\ 1 \\ 2 \\ version 1 \\ 05 Mar 2020 \\ Faculty Reviews are review articles written by the \\ prestigious Members of Faculty Opinions. The \\ articles are commissioned and peer reviewed \\ before publication to ensure that the final, \\ published version is comprehensive and \\ accessible. The reviewers who approved the final \\ version are listed with their names and \\ affiliations. \\ 1. Vera H Koch, University of São Paulo Medical \\ School, São Paulo, Brazil \\ 2. Salvator Arlandis, La Fe University and \\ Polytechnic Hospital, Valencia, Spain
}

Any comments on the article can be found at the end of the article. 
Corresponding author: Upeksha S Alwis (UpekshaSewwandi.alwis@ugent.be)

Author roles: Alwis US: Conceptualization, Investigation, Methodology, Visualization, Writing - Original Draft Preparation, Writing Review \& Editing; Monaghan TF: Conceptualization, Methodology, Visualization, Writing - Review \& Editing; Haddad R:

Conceptualization, Methodology, Visualization, Writing - Review \& Editing; Weiss JP: Conceptualization, Visualization, Writing - Review \& Editing; Roggeman S: Conceptualization, Visualization, Writing - Review \& Editing; Van Laecke E: Conceptualization, Writing - Review \& Editing; Vande Walle J: Conceptualization, Writing - Review \& Editing; Wein AJ: Conceptualization, Writing - Review \& Editing; Everaert K : Conceptualization, Methodology, Project Administration, Resources, Supervision, Visualization, Writing - Review \& Editing

Competing interests: Dr. Wein has served as an advisor/consultant for Avadel, GTX, Acquinox, Urovant, Medtronic, and Serenity within the last three years, outside the submitted work. Dr. Weiss is a consultant for Ferring, and the Institute for Bladder and Prostate Research, outside the submitted work. Dr. Everaert is a consultant and lecturer for Medtronic and Ferring and reports institutional grants from Allergan, Ferring, Astellas, and Medtronic, outside the submitted work. Dr Vande Walle reports institutional grants from Allergan, Astellas, and Ferring, and is a consultant and lecturer for Ferring and Astellas, outside the submitted work. Dr. Roggeman reports grants from Dr. Frederik Paulsen Chair, UGent-Ferring. Dr. Haddad reports personal fees and non-financial support from Astellas, MedDay Pharmaceuticals, Novartis Pharma SAS, Dentsply Sirona France, Pierre Fabre Medicament, Allergan France, Bayer HealthCare SAS and Vifor France SA, outside the submitted work. The other authors have nothing to disclose.

Grant information: We acknowledge the financial support from the Frederik Paulson Chair, Ghent University. The funders had no role in study design, data collection and analysis, decision to publish, or preparation of the manuscript.

Copyright: (c) 2020 Alwis US et al. This is an open access article distributed under the terms of the Creative Commons Attribution License, which permits unrestricted use, distribution, and reproduction in any medium, provided the original work is properly cited.

How to cite this article: Alwis US, Monaghan TF, Haddad R et al. Dietary considerations in the evaluation and management of nocturia [version 1; peer review: 2 approved] F1000Research 2020, 9(F1000 Faculty Rev):165

https://doi.org/10.12688/f1000research.21466.1

First published: 05 Mar 2020, 9(F1000 Faculty Rev):165 https://doi.org/10.12688/f1000research.21466.1 


\section{Introduction}

Nocturia, defined as the act of waking to void during the hours of intended sleep, is among the most common and bothersome lower urinary tract symptoms (LUTSs) ${ }^{1}$. Although the prevalence of nocturia increases with age ${ }^{2}$, nocturia is a common complaint among both men and women of all ages and backgrounds ${ }^{3}$. Nocturia is associated with an increased mortality rate and morbidity, owing largely to its direct negative impact on sleep architecture and daytime function and its role as an independent risk factor for falls and hip fractures in the elderly ${ }^{2}$.

Reducing fluid intake and caffeine and alcohol intake and improving sleep hygiene are involved in lifestyle modification in nocturia management ${ }^{2,4}$. In cases of nocturia refractory to conservative measures, the management of nocturia centers on a broad range of pharmacologic therapies, including antimuscarinics in the setting of concomitant overactive bladder (OAB), $\alpha$-blockers and $5 \alpha$-reductase inhibitors for men with benign prostatic hyperplasia (BPH), medication for improving sleep (for example, sedatives and melatonin), and antidiuretic therapy ${ }^{2,4}$.

However, in the progression from initial individualized behavioral modification and lifestyle interventions to pharmacologic treatments, the role of food and other nutrients is often overlooked. Urine is produced in order to regulate the body fluid homeostasis, electrolytes, the acid-base balance and to remove toxins and by-products 5 . Food and beverages which are the main dietary source of fluids, electrolytes (for example, sodium, potassium, or calcium), and other osmotically active substances (for example, urea and glucose) can therefore promote diuresis, contributing to nocturnal or 24-hour polyuria or both. Accordingly, the objective of this narrative review is to evaluate available data on the effect of dietary intake on the prevention and treatment of nocturia.

\section{Methodology}

This narrative review was based on a literature search in Web of Science, Embase, Medline, and Google Scholar databases with the keywords "nocturia", "LUTS", "diuresis", "natriuresis", "food", "diet", and "nutrients". The search was limited to articles published in the English language. No time limits were applied. Randomized controlled trials (RCTs), prospective observational studies, retrospective series, case reports, editorials, research letters, review articles, meeting abstracts, textbooks, and book chapters were included for this narrative review.

\section{Results}

Diet and nocturia

A summary of the effect of different types of food and beverages on nocturia is provided in Figure 1.

Fluid intake. Although food moisture constitutes a sizable minority of the total dietary fluid $\operatorname{load}^{6}$, the cumulative volume of all drinks consumed throughout the day constitutes a majority of total body water, and fluid intake volume is highly correlated with urine volume ${ }^{7}$. Moreover, a decrease in dietary fluid intake has been shown to significantly improve nocturia severity in well-controlled randomized prospective trials ${ }^{8}$. Consistently, individualized behavioral modification counseling has been shown to be an effective intervention in the treatment of clinically significant nocturia ${ }^{9,10}$, and expert consensus from the International Continence Society has indeed endorsed fluid management as being central to the initial evaluation and management of nocturia ${ }^{11}$.

Sodium intake. High dietary sodium intake leads to increased thirst and subsequent fluid intake. Thus, dietary sodium restriction is an increasingly popular lifestyle recommendation for improving nocturia severity ${ }^{12}$.

This effect of dietary sodium restriction on nocturnal voiding frequency has been shown in a non-RCT of elderly Japanese patients $(\mathrm{n}=321)$ with at least one nocturnal voiding episode and high dietary salt intake ( $\geq 8 \mathrm{~g} / \mathrm{day}$ for men and $\geq 7 \mathrm{~g} /$ day for women $)^{13}$ at baseline. A significant reduction in nocturia $(2.3 \pm 0.9$ to $1.4 \pm 1.0$ voids $)$ was observed in subjects who successfully reduced their mean salt intake from 10.7 to $8.0 \mathrm{~g} /$ day. Conversely, subjects whose mean salt intake increased from 9.6 to $11 \mathrm{~g} /$ day incurred a significant increase in nocturnal voiding severity $(2.3 \pm 1.1 \text { to } 2.7 \pm 1.1 \text { voids })^{13}$.

High dietary sodium intake in relation to nocturia has also been investigated in observational protocols. A cross-sectional clinical study evaluated the relationship between the daily salt intake (high salt [11.4 g/day] versus low salt [7.3 g/day]) and nocturia in 728 patients $^{14}$. Both daytime and nighttime voiding frequencies were significantly higher among the group with high sodium intake $(8.4 \pm 2.4$ and $2.2 \pm 1.3$, respectively) compared with the low-salt group $(6.9 \pm 2.5$ and $1.4 \pm 1.3$, respectively). Daytime and nighttime urine volumes among the high-salt group

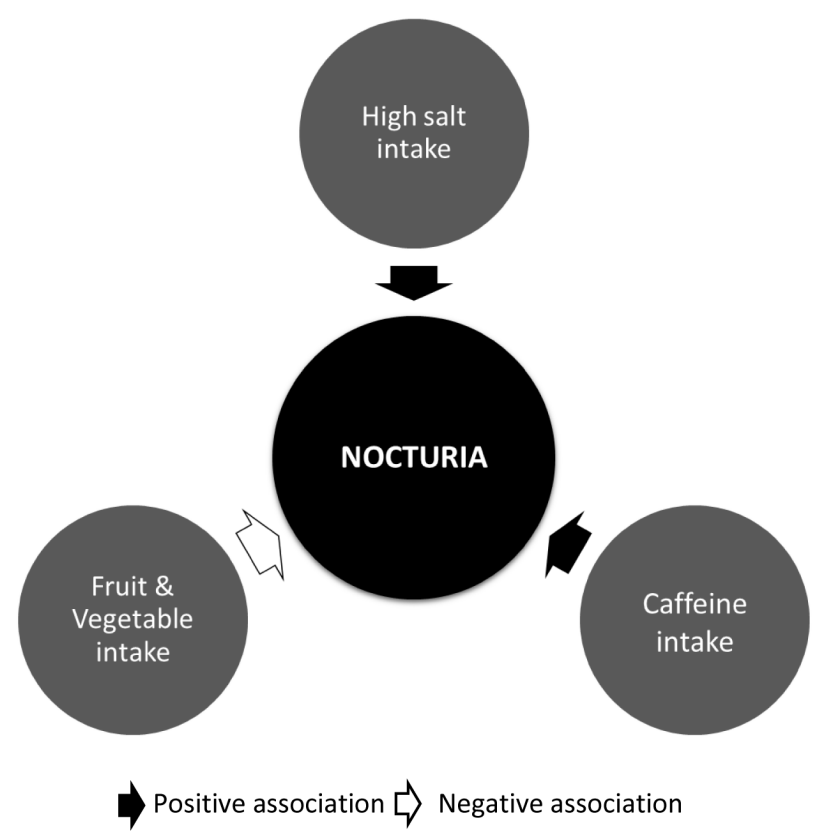

Figure 1. Effect of different types of food and beverages on nocturia. 
$(1811.7 \pm 477.7$ and $517.7 \pm 241.1 \mathrm{~mL}$, respectively) were significantly higher compared with those among the low-salt group $(1590 \pm 502.3 \text { and } 153.7 \pm 146.8 \mathrm{~mL} \text {, respectively })^{14}$.

Dietary salt intake is highly dependent on cultural, socioeconomic, and geographical factors and intra-individual dietary habits. However, the predominant source of dietary sodium tends to be attributable to processed foods $(70-75 \%)^{15}$, whereas salt added for flavoring or during cooking (10-15\%), coupled with that naturally present in unprocessed foods $(10-15 \%)^{15}$, typically constitutes but a minority of total dietary sodium intake. Reduction in dietary salt intake might be beneficial for nocturia patients with high salt intake-particularly in those who respond poorly to urologic medications ${ }^{13}$ - which involves careful consideration of all potential sources of excess dietary sodium.

Fruits and vegetables. Fruits and vegetables are rich sources of dietary nutrients such as vitamins, minerals, and fibers and many bioactive phytochemicals such as antioxidants and polyphenols ${ }^{16}$.

A longitudinal cohort study evaluated the association between consumption of fruits and vegetables and development of LUTS based on a validated Chinese version of the International Prostate Symptom Score (IPSS) ${ }^{16}$ for LUTS severity. Specifically, IPSS was assessed in 1564 elderly Chinese men at baseline and at 4-year follow-up encounters ${ }^{16}$. High fruit and vegetable intake (>350 g/1000 kcal per day) significantly reduced the "storage LUTS" (urinary frequency, urgency, and nocturia) (IPSS: $-0.448 \pm 0.230$ ) compared with the moderate intake of fruits and vegetables (250-350 g/1000 kcal per day). High intake of dark leafy vegetables (>50 g/1000 kcal per day) likewise significantly reduced storage symptoms (IPSS: $0.347 \pm 0.183$ ) compared with moderate intake $(25-50 \mathrm{~g} / 1000 \mathrm{kcal} \text { per day })^{16}$. Furthermore, compared with moderate intake, high intake of dark leafy vegetables significantly reduced the risk of incident storage symptoms (odds ratio (OR) 0.666, 95\% confidence interval (CI) 0.488-0.907). No association was observed between intake of soy foods, cruciferous vegetables, tomatoes, citrus fruits, and storage symptoms ${ }^{16}$.

Similarly, Furukawa et al. identified a negative association between vegetable intake (frequency) and nocturia in Japanese patients with type 2 diabetes (mean age of 61.7 years) ${ }^{17}$. In that prospective cohort study of 785 patients, increased vegetable intake habit was protective for clinically significant nocturia (at least two voids per night; OR $0.67,95 \%$ CI $0.48-0.94$ ) and for severe nocturia (at least three voids per night; OR 0.46 , 95\% CI $0.30-0.71)^{17}$. However, this study could not assess the dose-response relationship between vegetable intake and nocturia.

Caffeine intake. Caffeine belongs to the methylxanthine family of compounds and is present in a wide variety of foods and beverages $^{18}$. Caffeine is $100 \%$ bioavailable and excreted through urine $^{18}$. Caffeine is known to increase lower urinary tract smooth muscle contractility and stimulation of the central nervous system, and both mechanisms contribute to increased diuresis ${ }^{19}$. A cohort study on the effect of caffeinated beverages on urinary incontinence among Swedish female twins $(n=14,031)$ reported that high tea consumption ( $>3$ cups per day) was associated with an increased risk of nocturia (defined as at least two voids per night; OR 1.18, 95\% CI 1.01-1.38), but no association was observed between coffee consumption and nocturia ${ }^{19}$.

\section{Dietary effect on 24-hour polyuria}

Glycemic control. Many studies have reported on traditional foods, spices, and medicinal plants used by alternative medical customs and belief systems in the treatment of LUTS ${ }^{20-27}$. A non-RCT studied the effect of an Ayurvedic diet (traditional Indian medicine) on 30 patients with diabetes ${ }^{20}$. The diet was prepared on the basis of Ayurvedic diet, which included cereals (barley), legumes, vegetables, fruits, nuts and seeds, oils, and animal protein (eggs and milk), along with herbs, spices, herbal supplements, teas, and medicated milk (milk prepared with herbs). Following treatment, significant improvements were observed in clinical symptoms scores for polyuria $(1.3 \pm 1.022$ to $1.06 \pm 1.04)$, polydipsia $(1.1 \pm 0.959$ to $0.861 \pm 0.86)$, and polyphagia $(1.2 \pm 0.886$ to $1.06 \pm 0.944)^{20}$

Diuretic action of food. There is some expert opinion regarding certain foods/herbs in relation to urine production. In medieval Persian and Arabic medical classics, grass of Parnassus, blue leek, chickpea, wild rocket, cabbage, onion, cinnamon, Celtic spikenard, celery, and wild iris are referenced as highly effective diuretics ${ }^{24}$. In Ayurveda classics, a group of 10 herbs named "mutravirechaniya mahakashaya" (great extractives of diuretics) promised to effectively cure several common urinary disorders, including increased urinary frequency, urinary tract infections, and renal calculi ${ }^{28}$. Furthermore, plants containing cardiac glycosides or methylxanthines (coffee and tea) or plants with angiotensin-converting enzyme (ACE)-inhibiting activity (garlic, tea, and olive) have been reported for their potential diuretic activity $22,23,26$. However, very little knowledge is available on the potential bidirectional relationship between foods and diuresis.

\section{Dietary effect on sleep}

Melatonin is one of the key regulatory hormones of circadian rhythms $^{29}$. A dysregulation in the release of this hormone is involved in sleep disorders ${ }^{30}$. Low serum melatonin levels have been observed in patients with nocturia compared with patients without nocturia ${ }^{31}$. In a cross-sectional cohort study of 861 elderly men, those with a higher urinary concentration of 6-sulfatoxymelatonin (6-SMT) (the main metabolite of melatonin in the urine) incurred significantly lower odds for nocturia (adjusted OR 0.73 , 95\% CI $0.56-0.96)^{29}$.

Exogenous melatonin supplementation has been used to improve both sleep quality and nocturia ${ }^{2,29,31}$. A randomized clinical trial of 42 elderly patients with nocturia compared melatonin $(2 \mathrm{mg} / \mathrm{day})$ with a sedative, rilmazafone hydrochloride $(2 \mathrm{mg} / \text { day })^{31}$. The mean number of nocturnal voiding episodes significantly decreased in both the melatonin- and rilmazafone-treated groups (3.4 to 2.6 and 3.5 to 2.5 nocturnal voids, respectively). In a crossover RCT, 20 elderly men with bladder outflow obstruction (BOO) and nocturia (mean of 3.1 nocturia episodes per night) were treated with $2 \mathrm{mg}$ melatonin ${ }^{30}$. Following treatment, nocturia decreased in both the intervention 
and placebo groups (0.32 and 0.05 nocturnal voids, respectively). The rate of nocturia treatment response, defined as a reduction from baseline of at least 0.5 episodes per night, was significantly higher in the intervention group ${ }^{30}$.

Importantly, foods rich in nutrients are important in the synthesis of endogenous melatonin. Indeed, some of them act as precursors, cofactors, and activators in the production of this hormone, including tryptophan, B vitamins, magnesium, zinc, and polyunsaturated fatty acids. Furthermore, foods such as rice, barley, tomatoes, cranberry, strawberry, walnuts, olive oil, unprocessed cow milk, eggs, and fish are rich dietary sources of bioavailable melatonin ${ }^{32,33}$.

An increased concentration of melatonin in the blood and urine after ingestion of dietary melatonin has been reported in both animal and human studies ${ }^{32}$. A crossover study investigated the impact of dietary melatonin on serum melatonin concentration (SMC) in 12 healthy male subjects ${ }^{34}$. Participants consumed orange or pineapple juice (from $1 \mathrm{~kg}$ of fruits) or two whole bananas. Peak SMC levels were observed 120 minutes following fruit consumption and returned to baseline values 180 minutes after ingestion. SMC values significantly increased from baseline for the pineapple juice (48 versus $146 \mathrm{pg} / \mathrm{mL}$ ), orange juice (40 versus $151 \mathrm{pg} / \mathrm{mL}$ ), and banana (32 versus $140 \mathrm{pg} / \mathrm{mL})^{34}$.

Specific dietary habits, foods, and compounds have also been associated with changes in endogenous SMCs. Energy restriction $(<300 \mathrm{kcal}$ per day) has been shown to reduce nocturnal melatonin concentration by $20 \%$. Caffeine has been reported to possess both stimulatory and inhibitory effects on melatonin level ${ }^{32}$. Alcohol consumption has been shown to reduce nocturnal $\mathrm{SMC}^{32}$.

\section{Discussion}

Lifestyle interventions are an important first-line treatment for voiding dysfunction. Knowledge of therapeutic action of foods, spices, herbs, and minerals is commonly used by many alternative and complementary medicine systems $\mathrm{s}^{24,35}$. Moreover, the International Consultation on Incontinence has recognized the need for increased research on the conservative management of voiding dysfunction ${ }^{2}$. This study evaluated the dietary impact on nocturia as synthesized from currently available literature. Overall, there is evidence to suggest that certain foods, electrolytes, and specific compounds may contribute to the pathogenesis of nocturia, but there remains poor overall evidence with regard to specific conclusions and largely insufficient evidence to establish causality.

Nevertheless, this synthesis of current literature overviews several promising avenues for future investigation, particularly with respect to dietary sodium and fruits and vegetables. High dietary sodium intake increased nocturia in a non-RCT ${ }^{13}$, and this observation was further supported in an observational study ${ }^{14}$. High dietary intake of fruits and vegetables showed a negative association with nocturia, whereas high intake of tea showed a positive association with nocturia in observational studies.
Several potential mechanisms may contribute to the observed associations identified in this review. Fruits and vegetables are rich in antioxidant phytochemicals ${ }^{17}$ and thus may have a beneficial effect on nocturia, particularly in the setting of OAB, bladder outlet obstruction secondary to $\mathrm{BPH}$, and other urinary storage symptoms, which are important contributors to nocturia that may be mediated by inflammation ${ }^{36,37}$. Vegetable intake has also been reported to reduce post-prandial hyperglycemia, which is likewise associated with decreased oxidative stress and inflammation ${ }^{17}$. Thus, intake of vegetables might protect the prostate and bladder by preventing inflammation and oxidative damage ${ }^{17}$. Notably, intake of vegetables, fruits, vegetable fats, citrus juice, pumpkin seeds, bread, chicken, dietary isoflavone, and beer and intake levels of vitamin D, protein, and potassium demonstrated significant negative associations with $\mathrm{OAB}$ and $\mathrm{BPH}^{16,17,38}$.

Moreover, the relationship between foods and diuresis may be indirectly mediated by melatonin. Melatonin is a derivative of the essential amino acid tryptophan ${ }^{33}$. It is a neurotransmitter hormone that is critical for sleep maintenance and the regulation of circadian rhythm (day-night/sleep-wake cycle) $)^{29,31,32}$. Nighttime urination frequency follows this biological rhythm, as characterized by decreased urine production and increased bladder storage from the daytime to nighttime period ${ }^{29}$. Intake of cereals, vegetables, fruits, caffeine, and certain vitamins and minerals may modify melatonin production in the body ${ }^{32,34}$. Therefore, insufficiency in dietary melatonin-rich foods or dietary nutrients may compromise melatonin production in the body-especially in older adults since the production of melatonin decreases with $\operatorname{age}^{32}$. Future research is needed to explore the potentially significant benefits of dietary melatonin in nocturia patients with low serum melatonin.

Beyond this conventional wisdom that certain foods have diuretic and therapeutic properties, a wide range of phytochemicals such as phenolic compounds (flavonoids and tannins), alkaloids, coumarins, saponins, and glycosides have been reported for their potential diuretic activity through ACE inhibition or $\mathrm{Na}^{+} / \mathrm{K}^{+}$ ATPase-inhibiting activity ${ }^{23}$. Moreover, Liu et al. suggested that the observed beneficial association between fruit and vegetable intake and LUTS was not attributable to single micronutrients but to a collective effect and interactions of different nutrients available in the food ${ }^{16}$.

This narrative review highlights substantial areas for growth in the study of the diuretic properties of foods and beverages. Namely, the relationship between diet and nocturia must be interpreted in view of concomitant LUTS and systemic comorbidities such as obstructive sleep apnea which may influence the clinical phenotype of a patient's nocturnal voiding dysfunction ${ }^{39,40}$. Moreover, substantial dietary changes have been described to occur across the developmental period and throughout adulthood ${ }^{41}$ while the aging process itself may influence the pathogenesis of nocturia among patients with clinically relevant symptoms ${ }^{42}$.

\section{Conclusions}

At present, there is evidence to suggest that certain foods, electrolytes, and specific compounds may contribute to the pathogenesis 
of nocturia, but there remains poor overall evidence with regard to specific conclusions and largely insufficient evidence to establish causality. A greater understanding of the impact of food and nutrients on body fluid metabolism is important for improving the evaluation and treatment of nocturia. This area of study may also have direct implications with respect to other nocturnal voiding disorders such as enuresis, in which excess nocturnal urine volume is likewise a prominent underlying mechanism.
1. Hashim H, Blanker MH, Drake MJ, et al:: International Continence Society (ICS) report on the terminology for nocturia and nocturnal lower urinary tract function. Neurourol Urodyn. 2019; 38(2): 499-508. PubMed Abstract | Publisher Full Text

2. Everaert $\mathrm{K}$, Hervé $\mathrm{F}$, Bower $\mathrm{W}$, et al:: How can we develop a more clinically useful and robust algorithm for diagnosing and treating nocturia? ICI-RS 2017. Neurourol Urodyn. 2018; 37(S4): S46-S59.

PubMed Abstract | Publisher Full Text

3. Weiss JP: Nocturia: focus on etiology and consequences. Rev Urol. 2012; 14(3-4): 48-55.

PubMed Abstract | Free Full Text

4. $\quad \mathrm{F}$ Cornu JN, Abrams P, Chapple CR, et al.: A contemporary assessment of nocturia: definition, epidemiology, pathophysiology, and management--a systematic review and meta-analysis. Eur Urol. 2012; 62(5): 877-90. PubMed Abstract | Publisher Full Text | F1000 Recommendation

5. F Hashim H, Drake MJ: Basic concepts in nocturia, based on international continence society standards in nocturnal lower urinary tract function. Neurourol Urodyn. 2018; 37(S6): S20-S24.

PubMed Abstract | Publisher Full Text | F1000 Recommendation

6. EFSA Panel on Dietetic Products, Nutrition, and Allergies (NDA): Scientific Opinion on Dietary Reference Values for water. EFSA J. 2010; 8: 1459. Publisher Full Text

7. Perrier $\mathrm{E}$, Rondeau $\mathrm{P}$, Poupin $\mathrm{M}$, et al:: Relation between urinary hydration biomarkers and total fluid intake in healthy adults. Eur J Clin Nutr. 2013; 67(9): 939-43.

PubMed Abstract | Publisher Full Text | Free Full Text

8. Hashim H, Abrams P: How should patients with an overactive bladder manipulate their fluid intake? BJU Int. 2008; 102(1): 62-6. PubMed Abstract | Publisher Full Text

9. Cho SY, Lee SL, Kim IS, et al.: Short-term effects of systematized behavioral modification program for nocturia: a prospective study. Neurourol Urodyn. 2012; 31(1): 64-8.

PubMed Abstract | Publisher Full Text

10. Tani M, Hirayama A, Torimoto $\mathrm{K}$, et al:: Guidance on water intake effectively improves urinary frequency in patients with nocturia. Int $J$ Urol. 2014; 21(6): 595-600.

PubMed Abstract | Publisher Full Text

11. Everaert K, Hervé F, Bosch R, et al:: International Continence Society consensus on the diagnosis and treatment of nocturia. Neurourol Urodyn. 2019; 38(2): 478-98.

PubMed Abstract | Publisher Full Text

12. Monaghan TF, Michelson KP, Wu ZD, et al:: Dietary Sodium Restriction in Accordance with Cardiovascular Guidelines Improves Nocturia Severity in Patients at an Inner-City Cardiology Clinic. International Continence Society Annual Meeting. 2019.

Reference Source

13. $\mathrm{F}$ Tomohiro $\mathrm{M}$, Nakamura $\mathrm{Y}$, Yasuda $\mathrm{T}$, et al.: Effect of restricted salt intake on nocturia. Eur Urol Suppl. 2017; 16(3): e698. Publisher Full Text | F1000 Recommendation

14. $\mathrm{F}$ Matsuo $\mathrm{T}$, Miyata $\mathrm{Y}$, Sakai $\mathrm{H}$ : Daily salt intake is an independent risk factor for pollakiuria and nocturia. Int J Urol. 2017; 24(5): 384-9.

PubMed Abstract | Publisher Full Text | F1000 Recommendation

15. EFSA Panel on Dietetic Products, Nutrition, and Allergies (NDA): Tolerable Upper Intake Level on Vitamins and Minerals. 2006.

Reference Source

16. F Liu ZM, Wong CK, Chan D, et al:: Fruit and Vegetable Intake in Relation to Lower Urinary Tract Symptoms and Erectile Dysfunction Among Southern Chinese Elderly Men: A 4-Year Prospective Study of Mr OS Hong Kong. Medicine (Baltimore). 2016; 95(4): e2557.

PubMed Abstract | Publisher Full Text | Free Full Text | F1000 Recommendation

17. F Furukawa S, Sakai T, Niiya $T$, et al:: Dietary intake habits and the prevalence of nocturia in Japanese patients with type 2 diabetes mellitus. J Diabetes Investig. 2018; 9(2): 279-85.

PubMed Abstract | Publisher Full Text | Free Full Text | F1000 Recommendation

18. F Robinson D, Hanna-Mitchell A, Rantell A, et al:: Are we justified in suggesting change to caffeine, alcohol, and carbonated drink intake in lower urinary tract disease? Report from the ICI-RS 2015. Neurourol Urodyn. 2017; 36(4): 876-81.

PubMed Abstract | Publisher Full Text | F1000 Recommendation

19. Tettamanti G, Altman D, Pedersen NL, et al.: Effects of coffee and tea consumption on urinary incontinence in female twins. BJOG. 2011; 118(7): 806-13.

PubMed Abstract | Publisher Full Text | Free Full Text

20. Acharya RK, Upadhyay BN, Dwivedi LD: Dietary management in prameha. Anc Sci Life. 1996; 15(3): 176-89.

PubMed Abstract | Free Full Text

21. Sripanidkulchai $B$, Wongpanich $V$, Laupattarakasem $P$, et al.: Diuretic effects of selected Thai indigenous medicinal plants in rats. J Ethnopharmacol. 2001; 75(2-3): 185-90.

PubMed Abstract | Publisher Full Text

22. Dutta KN, Chetia P, Lahkar S, et al:: Herbal Plants Used as Diuretics: A comprehensive Review. J Pharm Chem Biol Sci. 2014; 2(1): 27-32. Reference Source

23. Gupta V, Arya V: A review on potential diuretics of Indian medicinal plants. $J$ Chem Pharm Res. 2011; 3(1): 613-620.

Reference Source

24. Shoja MM, Tubbs RS, Bosmia AN, et al.: Herbal diuretics in medieval Persian and Arabic medicine. J Altern Complement Med. 2015; 21(6): 309-20. PubMed Abstract | Publisher Full Text

25. F Kasote DM, Jagtap SD, Thapa D, et al.: Herbal remedies for urinary stones used in India and China: A review. J Ethnopharmacol. 2017; 203: 55-68. PubMed Abstract | Publisher Full Text | F1000 Recommendation

26. Wright $\mathrm{Cl}$, Van-Buren $\mathrm{L}, \mathrm{Kroner} \mathrm{Cl}$, et al:: Herbal medicines as diuretics: a review of the scientific evidence. J Ethnopharmacol. 2007; 114(1): 1-31. PubMed Abstract | Publisher Full Text

27. Marwat SK, Fazal-Ur-Rehman, Khan MA, et al.: Medicinal folk recipes used as traditional phytotherapies in district Dera Ismail Khan, KPK, Pakistan. Pakistan J Bot. 2011; 43(3): 1453-1462.

Reference Source

28. Khaire PA, Pansare TA, Kulkarni DV: A Pharmacognostic Review on Charakokta Mutravirechaniya Mahakashaya. Int J Res Ayurveda Pharm. 2015; 6(6): 737-44. Publisher Full Text

29. Obayashi K, Saeki K, Kurumatani N: Association between melatonin secretion and nocturia in elderly individuals: a cross-sectional study of the HEIJO-KYO cohort. J Urol. 2014; 191(6): 1816-21.

PubMed Abstract | Publisher Full Tex

30. Drake MJ, Mills IW, Noble JG: Melatonin pharmacotherapy for nocturia in men with benign prostatic enlargement. J Urol. 2004; 171(3): 1199-202. PubMed Abstract | Publisher Full Text

31. Sugaya $\mathrm{K}$, Nishijima $\mathrm{S}$, Miyazato $\mathrm{M}$, et al:: Effects of melatonin and rilmazafone on nocturia in the elderly. $J$ Int Med Res. 2007; 35(5): 685-91.

PubMed Abstract | Publisher Full Text

32. Peuhkuri K, Sihvola N, Korpela R: Dietary factors and fluctuating levels of melatonin. Food Nutr Res. 2012; 56: 17252. PubMed Abstract | Publisher Full Text | Free Full Text

33. Tan DX, Zanghi BM, Manchester LC, et al:: Melatonin identified in meats and other food stuffs: potentially nutritional impact. J Pineal Res. 2014; 57(2): 213-8.

PubMed Abstract | Publisher Full Text

34. Sae-Teaw M, Johns J, Johns NP, et al:: Serum melatonin levels and antioxidant capacities after consumption of pineapple, orange, or banana by healthy male volunteers. J Pineal Res. 2013; 55(1): 58-64. PubMed Abstract | Publisher Full Text

35. F Kumar S, Dobos GJ, Rampp T: The Significance of Ayurvedic Medicinal Plants. J Evid Based Complementary Altern Med. 2017; 22(3): 494-501. PubMed Abstract | Publisher Full Text | Free Full Text | F1000 Recommendation

36. Chughtai B, Lee R, Te A, et al:: Role of inflammation in benign prostatic hyperplasia. Rev Urol. 2011; 13(3): 147-50. PubMed Abstract | Free Full Text

37. Grover S, Srivastava A, Lee R, et al.: Role of inflammation in bladder function and interstitial cystitis. Ther Adv Urol. 2011; 3(1): 19-33. PubMed Abstract | Publisher Full Text | Free Full Text 
38. F Maserejian NN, Wager CG, Giovannucci EL, et al:: Intake of caffeinated, carbonated, or citrus beverage types and development of lower urinary tract symptoms in men and women. Am J Epidemiol. 2013; 177(12): 1399-410. PubMed Abstract | Publisher Full Text | Free Full Text | F1000 Recommendation

39. F Sousa AS, Veiga ML, Braga AA, et al.: Enuresis and overactive bladder in children: what is the relationship between these two conditions? Int Braz J Urol. 2016; 42(4): 798-802.

PubMed Abstract | Publisher Full Text | Free Full Text | F1000 Recommendation

40. Baird DC, Seehusen DA, Bode DV: Enuresis in children: a case based approach.
Am Fam Physician. 2014; 90(8): 560-8. PubMed Abstract

41. F Winpenny EM, van Sluijs EMF, White M, et al:: Changes in diet through adolescence and early adulthood: Iongitudinal trajectories and association with key life transitions. Int J Behav Nutr Phys Act. 2018; 15(1): 86. PubMed Abstract | Publisher Full Text | Free Full Text | F1000 Recommendation

42. Weiss JP, Blaivas JG, Jones M, et al.: Age related pathogenesis of nocturia in patients with overactive bladder. $J$ Urol. 2007; 178(2): 548-51; discussion 551. PubMed Abstract | Publisher Full Text 


\section{Open Peer Review}

\section{Current Peer Review Status:}

\section{Editorial Note on the Review Process}

Faculty Reviews are review articles written by the prestigious Members of Faculty Opinions. The articles are commissioned and peer reviewed before publication to ensure that the final, published version is comprehensive and accessible. The reviewers who approved the final version are listed with their names and affiliations.

\section{The reviewers who approved this article are:}

\section{Version 1}

\section{Salvator Arlandis}

Urology Department, La Fe University and Polytechnic Hospital, Valencia, Spain

Competing Interests: No competing interests were disclosed.

\section{Vera H Koch}

Pediatric Nephrology Unit, Instituto da Criança Hospital das Clinicas, University of São Paulo Medical School, São Paulo, Brazil

Competing Interests: No competing interests were disclosed.

The benefits of publishing with F1000Research:

- Your article is published within days, with no editorial bias

- You can publish traditional articles, null/negative results, case reports, data notes and more

- The peer review process is transparent and collaborative

- Your article is indexed in PubMed after passing peer review

- Dedicated customer support at every stage

For pre-submission enquiries, contact research@f1000.com 